\title{
Endovascular Treatment of Dural Arteriovenous Fistulas Using Transarterial Liquid Embolization in Combination with Transvenous Balloon-Assisted Protection of the Venous Sinus
}

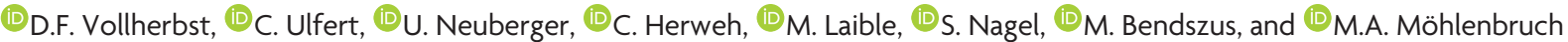

\begin{abstract}
BACKGROUND AND PURPOSE: Sinus-preserving endovascular embolization was described as a promising treatment technique for dural arteriovenous fistulas. Our aim was to report our single-center experience in patients with dural arteriovenous fistulas who were treated with transarterial liquid embolization in combination with transvenous balloon-assisted protection of the affected venous sinus.
\end{abstract}

MATERIALS AND METHODS: A retrospective analysis of a prospectively collected data base was performed. Demographic and clinical data, angiographic features of the dural arteriovenous fistulas, procedural parameters, complications, treatment success, follow-up imaging, and clinical outcome were assessed.

RESULTS: Twenty-two patients were treated in 25 procedures. All patients were symptomatic, of whom $81.8 \%$ presented with tinnitus; $9.1 \%$, with ocular symptoms; and 9.1\%, with headache. Most fistulas were located at the transverse and/or sigmoid sinus. The most frequent fistula type was Cognard IIa+b (40.9\%), followed by Cognard I (31.8\%) and Cognard IIa (27.3\%)/Borden I (59.1\%), followed by Borden II (40.9\%). The affected sinus could be preserved in all except for 1 patient in whom it was sacrificed in a second treatment procedure by coil embolization. The overall complete occlusion rate was $86.4 \%$. The overall complication rate was $20 \%$, with transient and permanent morbidity and mortality of $8 \%, 0 \%$, and $0 \%$, respectively. After a mean follow-up of 18 months, most patients (68.2\%) achieved complete symptom remission, $27.3 \%$ showed symptom relief, and $4.6 \%$ had stable symptoms.

CONCLUSIONS: Transarterial liquid embolization of dural arteriovenous fistulas in combination with transvenous balloon-assisted protection of the venous sinus is feasible and safe and offers high rates of occlusion and of symptom remission.

ABBREVIATION: dAVF $=$ dural arteriovenous fistula

D ural arteriovenous fistulas (dAVFs) are pathologic, usually acquired connections between dural arteries and dural venous sinuses or cortical veins, resulting in arteriovenous shunting of blood. The 2 major types of clinical presentation are either hemorrhage, with corresponding neurologic deficits, or venous hypertension, with the latter potentially resulting in a variety of symptoms, such as headache, pulsatile tinnitus, visual disturbances, cognitive decline, or seizures. ${ }^{1}$

Endovascular treatment is considered effective for dAVFs. ${ }^{2,3}$ Various endovascular treatment techniques have been and are currently being used, using either a transarterial, transvenous, or combined approach. ${ }^{2}$ The armamentarium of embolic agents in-

Received January 15, 2018; accepted after revision March 5.

From the Departments of Neuroradiology (D.F.V., C.U., U.N., C.H., M.B., M.A.M.) and Neurology (M.L., S.N.), Heidelberg University Hospital, Heidelberg, Germany.

Please address correspondence to Markus A. Möhlenbruch, MD, Department of Neuroradiology, Heidelberg University Hospital, INF 400, 69120 Heidelberg, Germany; e-mail: markus.moehlenbruch@med.uni-heidelberg.de

http://dx.doi.org/10.3174/ajnr.A5651 cludes liquid embolic agents, such as cyanoacrylates and ethylenevinyl copolymers, coils, and particles. ${ }^{2,3}$ In special situations, transient occlusion with balloon catheters can be used as an adjunct to conventional transarterial or transvenous embolization. When applied on the arterial side, they can be used for reduction of the blood flow of the fistula, for enhancement of distal migration of the embolic agent while simultaneously reducing the amount of reflux, and for improvement of embolization control. ${ }^{4-7}$ In the venous system, balloon catheters can be used for protecting the venous sinuses and nontarget veins from unwanted embolization. ${ }^{6,8-10}$ In dAVFs with a high risk for venous nontarget embolization, especially fistulas at the transverse or sigmoid sinus, this aspect is of particular importance because nontarget embolization risks occlusion of functionally relevant venous drainage, potentially leading to venous congestion, venous infarction, or intracerebral hemorrhage. ${ }^{11,12}$ Transarterial embolization in combination with transvenous balloon protection is a promising approach for the effective treatment of dAVFs with prevention of nontarget emboliza- 


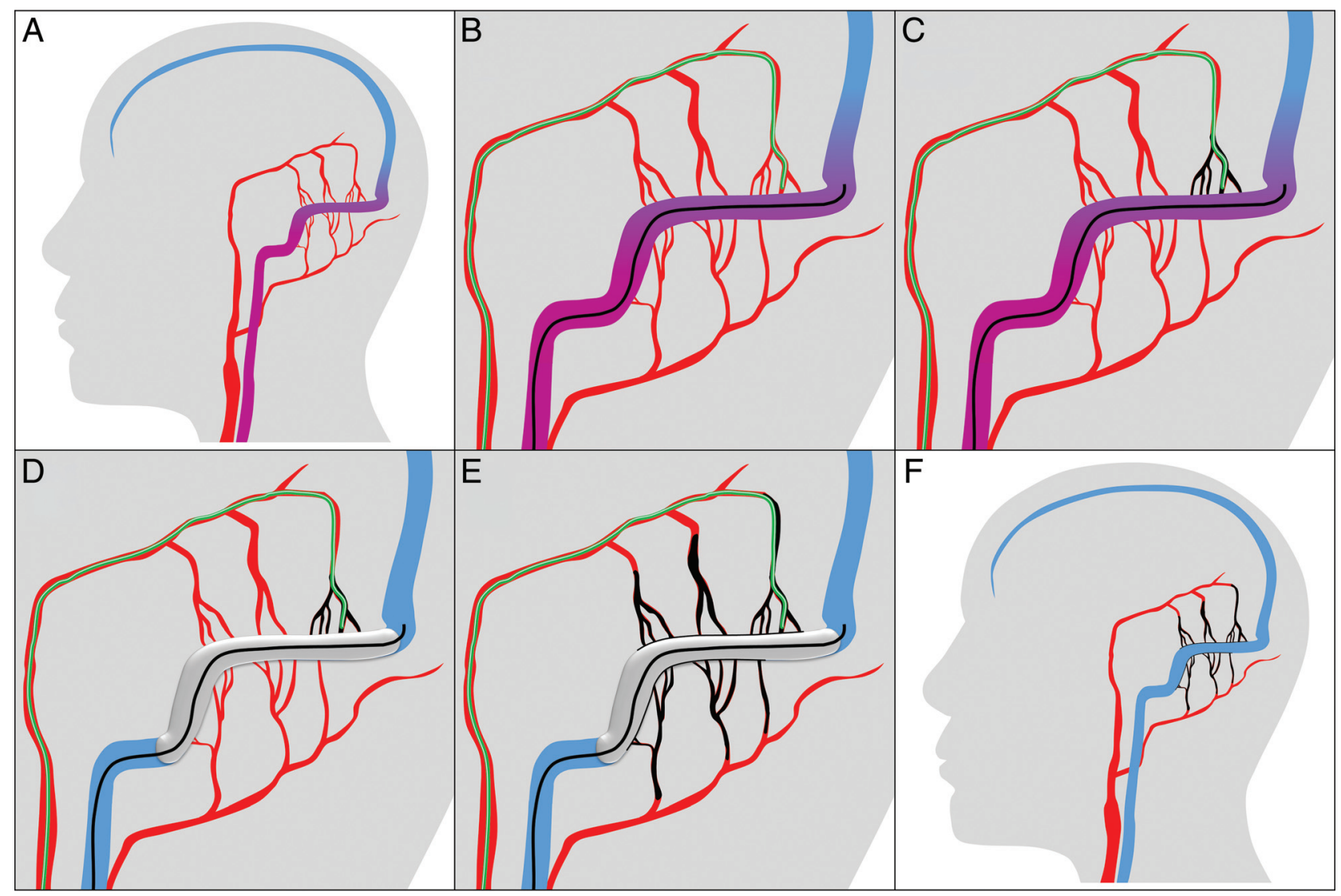

FIG 1. Schematic illustration of the treatment technique. $A$, The treatment technique is shown in the example of a Cognard I/Borden I $\mathrm{dAVF}$ located at the transverse and sigmoid sinuses with feeders from the occipital and middle meningeal arteries. $B$, After preinterventional diagnostic angiography, a balloon catheter (in black) is navigated into the affected sinus, and a microcatheter (in green) is navigated into the most promising feeder (in this example, the petrosquamosal branch of the middle meningeal artery). C, After superselective diagnostic angiographies via the microcatheter with and without balloon inflation, Onyx is injected under balloon deflation until the Onyx cast (in black) reaches the sinus. $D$, Subsequently, the balloon is inflated to prevent inadvertent embolization of the sinus and to enable retrograde embolization of the other arterial feeders. $E$, Onyx injection is continued under balloon inflation and deflation until embolization of all feeders is achieved. F, After the intervention, all feeding arteries are embolized and the sinus and the normal superficial veins (not shown) are preserved.

tion of the venous sinuses or normal superficial veins. So far, only a few studies on this technique with a relatively small number of patients are available. ${ }^{6,8,9,12,13}$

The aim of this study was to report our consecutive singlecenter experience of patients with dAVFs who were treated with transarterial liquid embolization in combination with transvenous balloon-assisted protection of the venous sinus and to present the feasibility, effectiveness, and safety of this treatment technique.

\section{MATERIALS AND METHODS \\ Clinical and Angiographic Analyses}

Study approval and informed consent for data collection were provided by the local ethics committee and the patients, respectively.

A retrospective analysis of a prospectively maintained patient data base was performed to identify all subsequent patients with dAVFs who were treated with endovascular transarterial liquid embolization in combination with transvenous balloon-assisted protection of the venous sinus from January 2011 to November 2017.

Patient demographics, clinical presentation, and clinical follow-up were assessed and recorded by a board-certified neurolo- gist, including preinterventional (on the day of the intervention) and postinterventional (at discharge and after 6 months) modified Rankin Scale scores. Angiographic features of the treated dAVFs were extracted, including location, type of fistula (according to the Cognard and Borden classifications ${ }^{14,15}$ ), and territories and number of the feeding arteries, by 2 experienced neuroradiologists (D.F.V. and M.A.M. with 5 and 12 years of experience, respectively), one of whom had no involvement in the treatment. Procedural parameters, such as the number of procedures, number of embolization positions, and the preservation of the venous sinus were documented. Peri- and postprocedural complications were assessed and graded as asymptomatic complications, transient symptomatic complications, and symptomatic complications with permanent neurologic deficits. The initial complete angiographic occlusion rate was assessed after the last treatment procedure. Overall complete occlusion was defined as complete occlusion of the dAVF at the last follow-up examination, diagnosed with digital subtraction angiography, which was performed 6 months after the last treatment, and/or MR imaging, which was performed before discharge and during the follow-up.

AJNR Am J Neuroradiol 39:1296-1302 Jul 2018 www.ajnr.org 
Table 1: Patient demographics, clinical presentation, and angiographic features of the treated dAVFs ${ }^{\mathrm{a}}$

\begin{tabular}{lc}
\hline Patient demographics & \\
Total No. of patients & 22 \\
Patient age (yr) & $55 \pm 15$ \\
Male/female ratio & $1: 1$ \\
Clinical presentation & \\
Symptomatic patients & $22(100 \%)$ \\
Hemorrhage & $1(4.6 \%)$ \\
Preinterventional mRS & $1 \pm 1$ \\
dAVF location & \\
Transverse and/or sigmoid sinus & $19(86.4 \%)$ \\
Superior sagittal sinus & $2(9.1 \%)$ \\
Marginal sinus & $1(4.6 \%)$ \\
dAVF classification & \\
Cognard I & $7(31.8 \%)$ \\
Cognard Ila & $6(27.3 \%)$ \\
Cognard Ila+b & $9(40.9 \%)$ \\
Borden I & $13(59.1 \%)$ \\
Borden II & $9(40.9 \%)$ \\
Feeder territories & \\
Middle meningeal artery & $21(95.5 \%)$ \\
Occipital artery & $21(95.5 \%)$ \\
Internal carotid artery (dural branches) & $19(86.4 \%)$ \\
Vertebral artery (dural branches) & $14(63.6 \%)$ \\
Superficial temporal artery & $11(50.0 \%)$ \\
Other angiographic features & \\
Bilateral feeders & $13(59.1 \%)$ \\
No. of feeder territories & $5 \pm 2$ \\
$\geq 20$ Feeding arteries ${ }^{b}$ & $19(86.4 \%)$ \\
$<20$ Feeding arteries ${ }^{b}$ & $3(13.6 \%)$ \\
\hline
\end{tabular}

${ }^{a}$ Data are presented as No. (relative frequency in \%) or mean \pm SD.

${ }^{b}$ Feeding arteries with a length of $\geq 10 \mathrm{~mm}$ (measured from the dural sinus).

\section{Patient Selection}

Transarterial liquid embolization in combination with transvenous balloon-assisted protection of the affected venous sinus was chosen as the primary treatment technique in patients with patency and functioning of the affected sinus and location of the fistula point within the sinus wall. Contraindications for transvenous balloon-assisted protection of the sinus were nonpatency or nonfunctioning of the sinus (for example, due to high-grade stenosis or complete occlusion) or location of the fistula point in a sinus compartment, which can potentially be embolized selectively while preserving the sinus. ${ }^{16}$

\section{Interventional Procedure}

All interventions were performed with the patient under general anesthesia in a biplane angiography suite (Artis Q or Artis zee; Siemens, Erlangen, Germany). During the procedure, patients were anticoagulated using heparin to achieve an activated clotting time of $>250$ seconds. After puncture, a $6 \mathrm{~F}$ introducer sheath was inserted into the right femoral artery and an $8 \mathrm{~F}$ introducer sheath was inserted into the left femoral vein. Preinterventional bilateral diagnostic angiographies of the internal and external carotid arteries and of the vertebral arteries were performed. A schematic illustration of the treatment technique is shown in Fig 1. A compliant, dimethyl sulfoxide-compatible, venous remodeling balloon (Copernic RC, $8 \times 80$ or $10 \times 80 \mathrm{~mm}$; Balt Extrusion, Montmorency, France) was navigated via the transvenous route into the affected sinus covering the arterial feeders. Subsequently, a dimethyl sulfoxide-compatible microcatheter (Marathon microcatheter, Covidien, Irvine, California; or SONIC, Balt Extrusion) was navigated into the most promising arterial feeder with the aim of achieving a distal position as close as possible to the fistula point.

Superselective diagnostic angiographies via the selected arterial feeder with and without balloon inflation were performed to assess the distribution into other arterial feeders and to determine the optimal embolization and balloon position. If one balloon was not sufficient for complete occlusion of the sinus or for complete coverage of the fistula, a second balloon was inserted. Afterward, transarterial embolization was performed using Onyx 18 (Covidien) under a roadmap technique. Simultaneously, the venous balloon was inflated and deflated with a maximum inflation time of 5 minutes. The balloon inflation pressure was manually adjusted to prevent migration of the embolic agent into the main sinus lumen and to simultaneously achieve retrograde penetration into the arterial feeders. After termination of the embolization procedure, diagnostic angiographies were performed via the feeder territories for treatment control.

\section{RESULTS}

Patient demographics, clinical presentation, and angiographic features of the treated dAVFs are summarized in Table 1.

Twenty-two patients diagnosed with dAVFs who were treated with endovascular transarterial liquid embolization in combination with transvenous balloon-assisted protection of the venous sinus from January 2011 to November 2017 were analyzed. All these patients were symptomatic, of whom $81.8 \%$ had tinnitus; $9.1 \%$, ocular symptoms; $9.1 \%$, headache; and $22.7 \%$, other symptoms. One patient $(4.6 \%)$ presented with an intracerebral hemorrhage. The fistulas were located at the transverse and/or sigmoid sinus $(86.4 \%)$, the sagittal superior sinus $(9.1 \%)$, or the marginal sinus (4.6\%). Most treated fistulas were low-grade without cortical venous reflux (59.1\%). According to the Cognard classification, the most frequent fistula type was IIa $+\mathrm{b}$ (40.9\%), followed by I (31.8\%) and IIa (27.3\%). According to the Borden classification, the most frequent fistula type was I (59.1\%), followed by II $(40.9 \%)$. The middle meningeal artery, the occipital artery (both $95.5 \%)$, and dural branches of the internal carotid artery (86.4\%) were the predominant arterial supplies.

Procedural parameters, treatment results, follow-up, and outcome are summarized in Table 2. An illustration of a representative case is shown in Fig 2.

Twenty-five treatment procedures were performed. In all patients, the treatment technique of the first procedure was transarterial Onyx embolization in combination with transvenous balloon protection. Two of the 3 patients who needed an additional treatment were again treated using the same technique, while for 1 patient, the second treatment consisted of coil embolization of the affected sinus. The reason for sinus occlusion in this patient was progressive thrombosis of the sinus, which was exclusively draining the fistula and was no longer involved in the normal venous drainage of the cranium. In 4 patients, 2 balloon catheters were required for adequate occlusion of the venous sinus or for complete coverage of the fistula. Most fistulas were embolized via the middle meningeal artery $(80.0 \%)$; the second most frequently selected feeder was the occipital artery (24.0\%).

The initial complete angiographic occlusion rate was $63.6 \%$, followed by 5 more complete spontaneous occlusions during the 
Table 2: Procedural parameters, treatment results, follow-up, and outcome ${ }^{a}$

\begin{tabular}{lc}
\hline No. of treatment procedures & \\
Total No. of treatment procedures & 25 \\
1 treatment procedure per patient & $19(86.4 \%)$ \\
2 treatment procedures per patient & $3(13.6 \%)$ \\
Selected feeder for embolization & \\
Middle meningeal artery & $18(80.0 \%)$ \\
Occipital artery & $5(24.0 \%)$ \\
Others & $2(8.0 \%)$ \\
No. of embolization positions & \\
1 & $20(80.0 \%)$ \\
C2 & $5(20.0 \%)$ \\
Complications & \\
Overall complications & $5(20.0 \%)$ \\
Asymptomatic complications & $3(12.0 \%)$ \\
Transient symptomatic complications & $2(8.0 \%)$ \\
Symptomatic complications with permanent neurologic deficits & $0(0 \%)$ \\
Follow-up & \\
Follow-up (mo) & $18 \pm 18$ \\
Postinterventional angiography available & $17(77.2 \%)$ \\
Postinterventional MRI available & $22(100 \%)$ \\
Angiographic outcome & \\
Initial complete angiographic occlusion & $14(63.6 \%)$ \\
Spontaneous occlusion after subtotal endovascular occlusion & $5(22.7 \%)$ \\
Time from last treatment to diagnosis of spontaneous occlusion (mo) & $3.5 \pm 6.0$ \\
Overall complete occlusion at last examination & $19(86.4 \%)$ \\
Residual fistula at last examination & $3(13.6 \%)$ \\
Clinical outcome & \\
Postinterventional mRS at discharge & $1 \pm 1$ \\
Postinterventional mRS 6 mo after treatment & $1 \pm 1$ \\
Complete symptom remission after treatment & $15(68.2 \%)$ \\
Symptom relief after treatment & $6(27.3 \%)$ \\
Stable symptoms after treatment & $1(4.6 \%)$ \\
Worsening of symptoms after treatment & $0(0 \%)$ \\
\hline
\end{tabular}

complications: 2 small infarctions, 2 small subdural hemorrhages (most likely caused by vessel perforation during navigation of the microcatheter into the respective arterial feeder or during traction of the microcatheter after embolization), and 1 small intracerebral hemorrhage $(<1 \mathrm{~cm}$ in diameter). In 1 patient with a small venous infarction, inadvertent embolization of the proximal part of the vein of Labbé could be identified as a suspected reason for the complication. For the small intracerebral hemorrhage, which was detected on a peri-interventional conebeam CT scan during the treatment of a patient with a Cognard IIa/ Borden I dAVF, stasis in a small temporal vein, caused by the temporary balloon occlusion, could be identified as a suspected reason for the complication. Three complications were asymptomatic, and 2 complications were symptomatic. The 2 patients with symptomatic complications had headaches, which were declining until discharge and no longer present 6 months after treatment. No complication with permanent neurologic deficits was recorded. No procedure-related cranial neuropathies were observed. follow-up period, resulting in an overall complete occlusion rate of $86.4 \%$. One of the 3 patients with residual fistula on angiography had a low-grade fistula (Cognard IIa/Borden I) and showed complete symptom remission at the last clinical examination. The remaining 2 patients refused further treatment because of symptom relief. For the 5 patients with spontaneous occlusion after treatment, the mean time from treatment to diagnosis of spontaneous occlusion was 106 days, ranging from 7 days to 14 months.

After a mean follow-up of 18 months, most patients (68.2\%) were free of symptoms, while $27.3 \%$ showed symptom relief and $4.6 \%$ had stable symptoms compared with the preinterventional status. Five patients still had symptoms (symptom relief for 4 patients and stable symptoms for 1 patient) despite complete occlusion of the fistula. These patients had nonpulsatile tinnitus $(n=2)$, headache $(n=2)$, and residual symptoms after severe venous congestion $(n=1)$. No patient died during the follow-up.

Postinterventional diagnostic angiography was performed in $77.2 \%$ of cases. From the patients without follow-up DSA, 3 patients refused further invasive diagnostic imaging because of complete symptom remission, and for 2 patients, follow-up DSA is still pending. Postinterventional MR imaging was performed in all patients.

Five procedure-related complications occurred, resulting in an overall complication rate of $20 \%$ (with respect to the number of treatment procedures). We recorded the following

\section{DISCUSSION}

Endovascular therapy has become the treatment of choice for most intracranial dAVFs and has considerably improved in recent years, which can - among other factors - be attributed to the introduction of new treatment techniques based on new devices, such as embolic agents, microcatheters, and balloon catheters. ${ }^{2,3,17}$ More recently, the strategy of neuroendovascular treatment aims to eliminate the respective pathology with preservation of the surrounding healthy vasculature. A promising technique for avoiding inadvertent occlusion of normal veins during transarterial embolization of dAVFs, which was first described by Shi et $\mathrm{al}^{13}$ in 2009, is the transient placement of a balloon in the affected venous sinus. ${ }^{6,8-10}$ The studies with the highest case numbers reporting this technique are those by Piechowiak et $\mathrm{al}^{6}$ and Ertl et $\mathrm{al}^{12}$ in 2017. Piechowiak et $\mathrm{al}^{6}$ conducted a retrospective study of 9 patients with fistulas of the transverse and sigmoid sinuses who were treated using a technique that is similar to the technique described here. However, they used balloon assistance on both the venous and the arterial sides. Ertl et $\mathrm{al}^{12}$ compared sinus-occluding and sinus-preserving endovascular treatment techniques for dAVFs, reporting on a subgroup of 11 patients treated with transarterial Onyx embolization combined with transvenous balloon-assisted protection of the venous sinus. In our retrospectively analyzed and prospectively maintained data base, 22 patients treated with transarterial liquid embolization in combination with transvenous balloon-assisted protection of the 


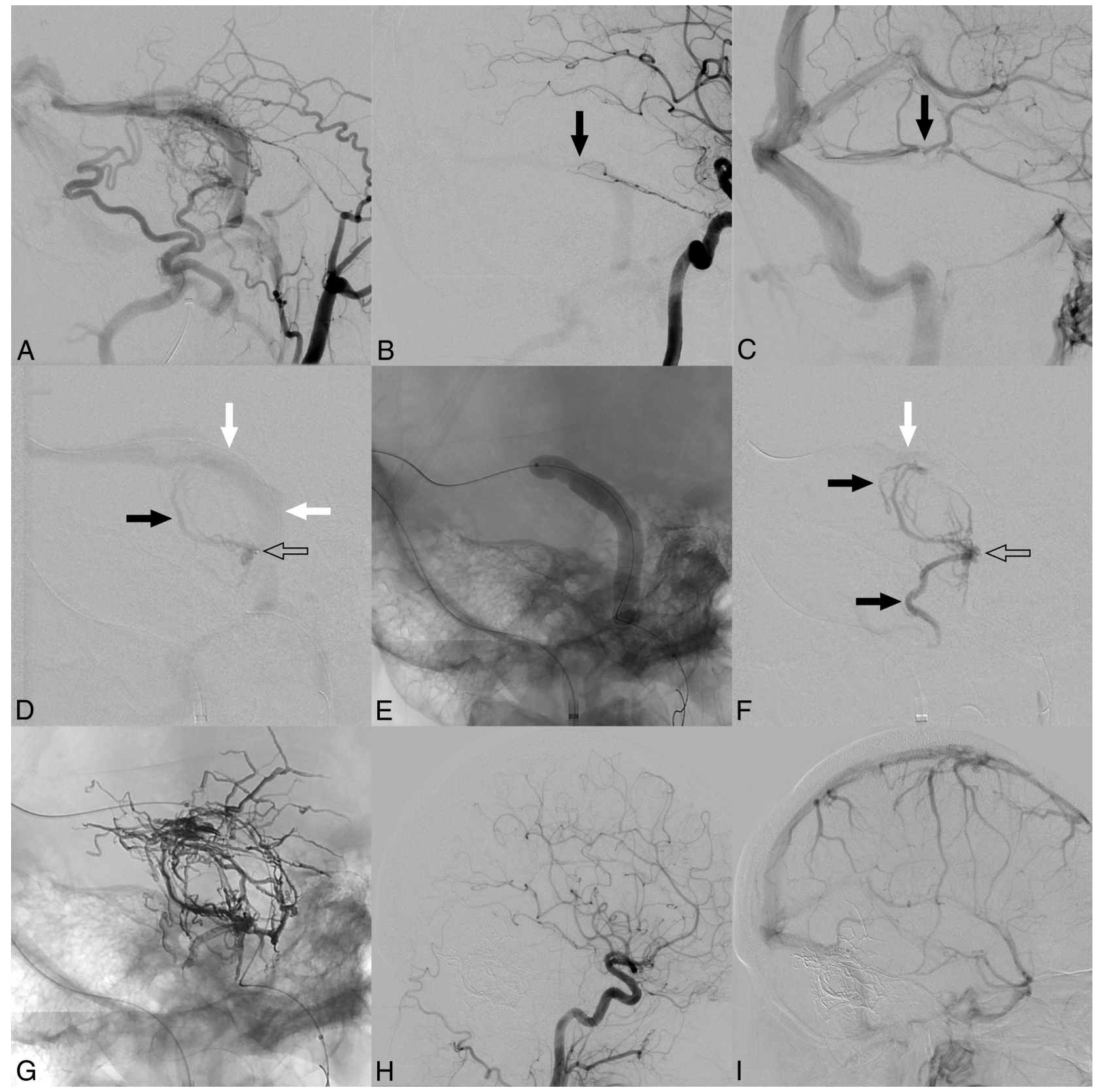

FIG 2. Illustration of a representative case. A, Right external carotid artery angiogram shows a Cognard Ila $+b /$ Borden II dAVF located at the transverse and sigmoid sinuses with multiple feeding arteries out of numerous vascular territories. $B$, Right internal carotid artery angiogram shows dural branches of the internal carotid artery feeding the fistula (black arrow). C, Venous phase of B. Note the proximity of the fistula point (black arrow in B) to the junction of the vein of Labbé and of the inferior temporal veins into the sinus (black arrow). For successful treatment of the dAVF, the fistula point should be embolized while simultaneously preserving these veins. $D$, Superselective angiogram without balloon inflation via the feeder that was selected for embolization, the mastoid branch of the occipital artery (microcatheter tip marked with an open arrow). There is drainage via the sinus (white arrows) and only slight filling of the adjacent feeders (black arrow). E, Lateral x-ray shows the inflated balloon. $F$, Superselective angiogram after balloon inflation (microcatheter tip marked with an open arrow). Due to the temporary occlusion of the sinus, which shows only minimal enhancement at the edge of the balloon (white arrow) at the junction of the vein of Labbé and the inferior temporal veins $(C)$, nearby feeders show marked filling of contrast agent (black arrows). The angiograms with the inflated balloon serve as a test injection to estimate the distribution of the subsequently injected liquid embolic agent. G, Onyx cast after embolization with distribution of the embolic agent in all feeding artery territories. Common carotid artery angiogram of the arterial $(H)$ and venous (I) phases 6 months after treatment shows complete occlusion of the fistula and patency of the venous sinuses and the normal superficial veins.

venous sinus were analyzed, and the feasibility, effectiveness, and safety of this treatment technique were investigated.

Except for 1 patient in our study in whom the affected sinus was occluded by coil embolization, preservation of the sinus could be achieved in all procedures. In the above-mentioned studies, the postinterventional patency of the respective sinus was not specifically reported. $6,12,13$

The described embolization technique promotes the preservation of the normal venous structures. In addition, another major advantage of the technique is described here. Not only is the arte- 
rial feeder through which the injection is performed being embolized but feeders from other arterial territories with connection to the respective sinus segment are also embolized in a retrograde manner by migration of embolic agent along the balloon and the sinus wall into the feeders. As a result, feeding arteries that are difficult or technically impossible to catheterize can be easily embolized and the number of arterial feeders to be catheterized can be reduced, potentially lowering the risk of periprocedural technical complications and also reducing the procedure time. Accordingly, in most cases in our study, only 1 embolization position was necessary for complete or near-complete embolization of the dAVFs. This is important because most of the dAVFs of the transverse and sigmoid sinuses have multiple feeders, ${ }^{18}$ as was the case in our series, in which $86 \%$ of the treated fistulas had $>20$ arterial feeding arteries. In this context, besides the facilitation of embolization of feeding arteries, this treatment technique also bears the risk of inadvertent embolization of cortical veins draining into the sinus. To prevent this complication, these veins must be carefully observed during the embolization, and if necessary, the balloon must be repositioned or another arterial feeder selected for embolization.

The overall complete occlusion rate of $86 \%$ in our series is comparable with the results of Piechowiak et al, ${ }^{6}$ who achieved complete occlusion or substantial flow reduction in $89 \%$ of patients treated with balloon-assistance on the arterial and venous sides. Similarly, Ertl et al $^{12}$ reported a complete occlusion rate of $71 \%$ for sinus-preserving endovascular treatments (not further subdivided with respect to the specific treatment technique).

Most of the fistulas in our series were low-grade without cortical venous reflux. For this type of fistula, the risk of bleeding is relatively low; therefore, substantial relief or complete remission of symptoms is the main aim of the treatment. ${ }^{19}$ The high rate of complete symptom remission and symptom relief of $95 \%$ in our study is in accordance with the results of recently published studies and underlines the effectiveness of endovascular embolization for the treatment of this type of dAVF. ${ }^{3,6,12}$

A significantly lower complication rate for sinus-preserving than for sinus-occluding techniques has been reported in a recently published study ( $0 \%$ versus $33 \%$ ), however, with a higher rate of permanent fistula occlusion for sinus-occluding techniques. ${ }^{12}$ In our study, the overall complication rate was $20 \%$ without any permanent neurologic deficits. Of the 5 complications that occurred in the present study, 2 can be attributed to the balloon occlusion of the venous sinus: 1 case of venous infarction due to inadvertent embolization of the proximal part of the vein of Labbé (facilitated by the balloon occlusion) and 1 case of intracerebral hemorrhage due to stasis of a small temporal vein caused by the temporary balloon occlusion itself. For the second patient who developed a venous infarction, no specific reason could be identified; however, the 2 above-mentioned mechanisms might also have contributed to this complication. To prevent procedure-related complications, as mentioned above, special attention should be paid to cortical veins draining into the affected sinus because inadvertent occlusion of these structures (both by inadvertent embolization and by too long temporary balloon occlusion) can lead to venous congestion and/or hemorrhage. The low rate of symptomatic complications is in line with data from other studies of sinus-preserving and sinus-occluding techniques with and without balloon-assistance. 3,5,6,12,20 $^{2}$

A potential limitation of this study is its relative low case number. However, to the best of our knowledge, this is the largest study reporting on this treatment technique. Furthermore, the study was conducted in a single institution with retrospective analysis of prospectively maintained data, which is a potential limitation on the study findings.

\section{CONCLUSIONS}

Transarterial liquid embolization in combination with transvenous balloon-assisted protection of the venous sinus is feasible and safe for the treatment of dAVFs and offers high rates of complete occlusion and of complete symptom remission or relief. Further studies with higher case numbers and long-term follow-up are necessary to further assess the value of this treatment technique.

Disclosures: Dominik F. Vollherbst-UNRELATED: Travel/Accommodations/Meeting Expenses Unrelated to Activities Listed: MicroVention, Stryker*. Christian Ulfert-UNRELATED: Travel/Accommodations/Meeting Expenses Unrelated to Activities Listed: MicroVention, Stryker. Christian Herweh-UNRELATED: Consultancy: Brainomix, Oxford, UK, Comments: $<€ 10,000$. Simon Nagel—UNRELATED: Consultancy: Brainomix, Boehringer Ingelheim; Payment for Lectures Including Service on Speakers Bureaus: Pfizer, Medtronic, Bayer AG. Martin Bendszus_UNRELATED: Board Membership: Data and Safety Monitoring Board for Vascular Dynamics, Guerbet, Boehringer Ingelheim; Consultancy: Codman, Roche Diagnostics, Guerbet, Boehringer Ingelheim, Braun; Grants/Grants Pending: DFG, Hopp Foundation, Novartis, Siemens, Guerbet, Stryker, Covidien*; Payment for Lectures Including Service on Speakers Bureaus: Novartis, Roche Diagnostics, Guerbet, Teva Pharmaceutical Industries, Bayer AG, Codman. Markus A. Möhlenbruch-UNRELATED: Board Membership: Codman; Consultancy: Medtronic, MicroVention, Stryker; Payment for Lectures Including Service on Speakers Bureaus: Medtronic, MicroVention, Stryker. *Money paid to the institution.

\section{REFERENCES}

1. Gross BA, Du R. The natural history of cerebral dural arteriovenous fistulae. Neurosurgery 2012;71:594-602; discussion 602-03 CrossRef Medline

2. Rammos S, Bortolotti C, Lanzino G. Endovascular management of intracranial dural arteriovenous fistulae. Neurosurg Clin N Am 2014;25: 539-49 CrossRef Medline

3. Gross BA, Albuquerque FC, Moon K, et al. Evolution of treatment and a detailed analysis of occlusion, recurrence, and clinical outcomes in an endovascular library of $\mathbf{2 6 0}$ dural arteriovenous fistulas. J Neurosurg 2017;126:1884-93 CrossRef Medline

4. Spiotta AM, Miranpuri AS, Vargas J, et al. Balloon augmented Onyx embolization utilizing a dual lumen balloon catheter: utility in the treatment of a variety of head and neck lesions. J Neurointerv Surg 2014;6:547-55 CrossRef Medline

5. Chiu AH, Aw G, Wenderoth JD. Double-lumen arterial balloon catheter technique for Onyx embolization of dural arteriovenous fistulas: initial experience. J Neurointerv Surg 2014;6: 400-03 CrossRef Medline

6. Piechowiak E, Zibold F, Dobrocky T, et al. Endovascular treatment of dural arteriovenous fistulas of the transverse and sigmoid sinuses using transarterial balloon-assisted embolization combined with transvenous balloon protection of the venous sinus. AJNR Am J Neuroradiol 2017;38:1984-89 CrossRef Medline

7. Kim JW, Kim BM, Park KY, et al. Onyx embolization for isolated type dural arteriovenous fistula using a dual-lumen balloon catheter. Neurosurgery 2016;78:627-36 CrossRef Medline

8. Jittapiromsak P, Ikka L, Benachour N, et al. Transvenous balloon- 
assisted transarterial Onyx embolization of transverse-sigmoid dural arteriovenous malformation. Neuroradiology 2013;55:345-50 CrossRef Medline

9. Zhang Y, Li Q, Huang QH. Embolization of a superior sagittal sinus dural arteriovenous fistula under intrasinus balloon protection: a case report. Interv Neuroradiol 2015;21:94-100 CrossRef Medline

10. Kerolus MG, Chung J, Munich SA, et al. An Onyx tunnel: reconstructive transvenous balloon-assisted Onyx embolization for dural arteriovenous fistula of the transverse-sigmoid sinus. J Neurosurg 2017 Nov 17:1-6. [Epub ahead of print] CrossRef Medline

11. Choi BJ, Lee TH, Kim CW, et al. Reconstructive treatment using a stent graft for a dural arteriovenous fistula of the transverse sinus in the case of hypoplasia of the contralateral venous sinuses: technical case report. Neurosurgery 2009;65:E994-96; discussion E996 CrossRef Medline

12. Ertl L, Brückmann H, Kunz M, et al. Endovascular therapy of lowand intermediate-grade intracranial lateral dural arteriovenous fistulas: a detailed analysis of primary success rates, complication rates, and long-term follow-up of different technical approaches. J Neurosurg 2017;126:360-67 CrossRef Medline

13. Shi ZS, Loh Y, Duckwiler GR, et al. Balloon-assisted transarterial embolization of intracranial dural arteriovenous fistulas. J Neurosurg 2009;110:921-28 CrossRef Medline

14. Cognard C, Gobin YP, Pierot L, et al. Cerebral dural arteriovenous fistulas: clinical and angiographic correlation with a revised classi- fication of venous drainage. Radiology 1995;194:671-80 CrossRef Medline

15. Borden JA, Wu JK, Shucart WA. A proposed classification for spinal and cranial dural arteriovenous fistulous malformations and implications for treatment. J Neurosurg 1995;82:166-79 CrossRef Medline

16. Piske RL, Campos CM, Chaves JB, et al. Dural sinus compartment in dural arteriovenous shunts: a new angioarchitectural feature allowing superselective transvenous dural sinus occlusion treatment. AJNR Am J Neuroradiol 2005;26:1715-22 Medline

17. Serulle Y, Miller TR, Gandhi D. Dural arteriovenous fistulae: imaging and management. Neuroimaging Clin N Am 2016;26:247-58 CrossRef Medline

18. Nishijima M, Takaku A, Endo S, et al. Etiological evaluation of dural arteriovenous malformations of the lateral and sigmoid sinuses based on histopathological examinations. J Neurosurg 1992;76: 600-06 CrossRef Medline

19. Davies MA, Ter Brugge K, Willinsky R, et al. The natural history and management of intracranial dural arteriovenous fistulae, Part 2: aggressive lesions. Interv Neuroradiol 1997;3:303-11 CrossRef Medline

20. Rangel-Castilla L, Barber SM, Klucznik R, et al. Mid and long term outcomes of dural arteriovenous fistula endovascular management with Onyx: experience of a single tertiary center. J Neurointerv Surg 2014;6:607-13 CrossRef Medline 